\title{
¿Fenomenología o gnosis? El límite fenomenológico del acceso a la relación religiosa en la filosofía del cristianismo de M. Henry
}

\section{Phenomenology or Gnosis? The Phenomenological Limit of the Access to the Religious Relationship in M. Henry's Philosophy of Christianity}

\author{
Ángel Enrique GARRIDO-MATURANO \\ (Consejo Nacional de Investigaciones Científicas y Técnicas [CONICET] - Instituto de \\ Investigaciones Neohistóricas [IIGHI], Argentina)
}

Recibido: $18 / 12 / 2010$

Aceptado: 15/11/2011

\section{Resumen}

El artículo se propone determinar el límite entre fenomenología y gnosis en la filosofía del cristianismo de M. Henry. Para ello analiza la cuestión del Archi-hijo en Soy yo la verdad, la de Archi-carne en Encarnación y la de la legitimación de las palabras que Cristo pronuncia sobre sí mismo en Palabras de Cristo. El análisis muestra, en primer lugar, en qué medida el tratamiento de estas tres cuestiones supera el límite estrictamente fenomenológico del pensamiento y remite a una gnosis o experiencia de fe particular. En segundo lugar, explicita cómo, independientemente de esta gnosis, la intuición henryana acerca de la esencia de la vida abre un acceso fenomenológico genuino a la relación religiosa.

Palabras clave: Henry, fenomenología, fe, gnosis, vida, carne, autoafectividad, religión.

\begin{abstract}
The article attempts to draw the line between phenomenology and gnosis in Michel Henry's phenomenology of christianity. With this purpose, it analyzes the problem of the Arch-Son in C'est moi la vérité, of the Arch-Flesh in Encarnation,
\end{abstract}


and of the legitimation of the words that Christ delivers about Himself in Paroles $d u$ Christ. The analysis shows first how the treatment of these issues surpases the strictly phenomenological limits of thought and refers to a gnosis or the experience of a particular faith. Secondly, the article explains how, independently of this gnosis, Henry's intuition of the structure of life opens a genuine phenomenological access to the religious relationship.

Keywords: Henry, phenomenology, gnosis, faith, life, flesh, self-affectivity, religion.

\section{Introducción temática y perspectiva metódica}

Michel Henry falleció el 3 de julio de 2002 a la edad de 80 años. Pronto se habrán de cumplir ya ocho de su desaparición. La historia de la filosofía le es y le será por siempre deudora de una intuición genial, que él formuló aguda y desarrolló obsesivamente, con una sistematicidad y profundidad rara vez vistas, ya en 1963, en una obra que podríamos calificar, desde un punto de vista estrictamente fenomenológico, como su obra fundamental: La esencia de la manifestación. ${ }^{1}$ Esa intuición genial era la de la esencia de la vida. Para Henry el aparecer se desdobla. Por un lado se manifiestan los entes del mundo y, por otro, se manifiesta la vida. En la manifestación de los entes mundanos impera la dualidad: una cosa es lo que se muestra, el fenómeno, y por otro aquel "afuera" trascendente en el que se muestra lo que se muestra, a saber, el horizonte de visibilidad, proyectado extáticamente por el sujeto, que determina el cómo del aparecer del fenómeno, esto es, el mundo. El mundo constituye, así, aquella esencia de la manifestación del fenómeno, diferente del fenómeno mismo y de su manifestación, en tanto el ser de lo que se manifiesta está dado por el plexo de sentido en el que se manifiesta y que con-forma las condiciones de posibilidad de su manifestación. Lo propio de esta forma de manifestación radica, pues, en que la esencia de la manifestación -el mundo- y lo que se manifiesta -el fenómeno- son diferentes. El fenómeno no se revela a sí mismo ni en sí mismo: se revela al sujeto y en el afuera del mundo. Por otro lado se manifiesta la vida. Su modo de manifestación es radicalmente diferente del aparecer de los entes en el mundo, porque en ella impera la identidad absoluta entre la manifestación y lo que se manifiesta; y porque tal manifestación se cumple en una absoluta inmanencia. La vida no revela otra cosa que sí, como lo hace el mundo, que revela el ser del ente que en él se manifiesta, sino que se revela a sí misma en la auto-experiencia afectiva de sí que tiene cada viviente. El viviente se experimenta a sí mismo,

${ }^{1}$ Henry, M. : L'essence de la manifestation (2 tomos), París, Presses Universitaires de France, 1963. Sigla $E M$. 
experimenta su propia vida y, en esa experiencia, la vida se experimenta a sí misma, se auto-afecta. Aquí la esencia de la vida -el experimentarse a sí misma, el sentirse a sí misma viviente- y la manifestación de la vida -nuevamente el sentirse o experimentarse a sí misma en la inmanencia de la auto-afección- son lo mismo. En ella la esencia de la manifestación y la manifestación de la esencia son una y la misma cosa. La vida, a diferencia de los fenómenos del mundo, no revela su esencia en un "afuera" a algo o alguien diferente de sí; su esencia es revelarse a sí misma en la experiencia inmanente de sí. Vivir significa sentirse a sí mismo, revelarse a sí o, en otros términos, auto-afectarse. El mundo y los entes son, pero no experimentan su ser ni se manifiestan a sí mismos. La vida es vida porque se experimenta a sí misma viviendo y, haciéndolo, se auto-manifiesta. Declara Henry: "Esto que tiene la experiencia de sí, lo que [se revela como] gozo de sí y no es otra cosa que este puro gozo de sí mismo, que esta pura experiencia de sí, es la vida"2. En el haber descubierto que la esencia de la vida es fenomenológica, en cuanto consiste en el puro aparecer a sí, e inmanente en tanto -a diferencia del mundo- aparece a sí misma en el sentimiento de sí, consiste, dicho apuradamente, la intuición genial de la Esencia de la manifestación. Ahora bien, en sus tres últimas obras: C'est moi. La verité $^{3}$, Incarnation ${ }^{4}$ y Paroles $d u$ Christ $^{5}$, Henry aplica su comprensión filosófica de la vida a los evangelios y, particularmente, al de San Juan, y despliega, así, una filosofía del cristianismo, que, para él, no es sino la expresión más profunda y directa de la esencia de la vida.

Las consideraciones que siguen se centrarán en estas tres últimas obras de Henry y las releerán con un objetivo preciso y desde ciertos presupuestos metodológicos específicos, por lo que tal vez no le sean útiles al lector que busque una introducción o una exégesis relativamente completa y sistemática de estos tres libros 6 . El objetivo, expresado de modo positivo, radica en determinar en qué medi-

\footnotetext{
2 EM, p. 354.

${ }^{3}$ Henry, M.: C'est moi. La verité. Pour une philosophie du christianisme, París, Éditions Du Seuil, 1996. Sigla: $M V$. Hay traducción española: Yo soy la verdad. Para una filosofía del cristianismo, Salamanca, Sígueme, 2001. (Aquí citaremos de acuerdo con la versión original francesa en traducción propia).

${ }^{4}$ Henry, M.: Incarnation. Une philosophie de la chair, París, Éditions du seuil, 2000. Hay traducción española de J. Teira, G. Fernández y R. Ranz: Encarnación. Una filosofia de la carne, Salamanca, Sígueme, 2001. Sigla: I. (Aquí citaremos de acuerdo con la traducción española).

5 Henry, M.: Paroles du Christ, París, Éditions du Seuil, 2002. Sigla PC. Hay trad española de J. Teira y R. Ranz: Palabras de Cristo, Salamanca, Sígueme, 2004. (Aquí citaremos de acuerdo con la traducción española).

${ }^{6}$ Aquellos que quieran introducirse a la fenomenología de M. Henry y, en particular, a su filosofía del cristianismo, encontrarán un resumen temático, ordenado genéticamente, de los tres libros que el autor dedica a la cuestión en la obra de Vidalin, A.: La Parole de la Vie. La phénoménologie de Michel Henry et l'intelligence chrétienne des Écritures, París, Éditions Parole et Silence, 2006, especialmente pp. 73-134.
} 
da la filosofía del cristianismo de Henry ofrece un fundamento filosófico para un acceso no confesional (esto es, independiente de la creencia en cualquier revelación histórica positiva o en cualquier dogma de una confesión determinada) y fenomenológico (esto es, que encuentra su legitimación en la descripción de experiencias que son propias de todo hombre en cuanto tal) a la relación religiosa. Expresado negativamente este mismo objetivo podría formularse así: determinar en qué medida la comprensión de la relación del hombre con Dios - de la relación religiosa- en el pensamiento de Henry trasciende el marco fenomenológico y resulta de una experiencia personal de fe o una gnosis particular. Este objetivo y la clave de lectura que ofrece aspira a moverse, entonces, en un límite y desde el límite quiere diferenciar lo que se sitúa de un lado y del otro del propio límite: lo que, de un lado, puede caracterizarse como la apertura de un acceso filosófico a la relación religiosa, esto es, de una legitimación fenomenológica de la razonabilidad de la esperanza religiosa, y, del otro, lo que puede leerse como el resultado de la elaboración especulativa de una fe particular. Tal objetivo presupone y está íntimamente vinculado con una perspectiva metodológica específica, que podría denominarse fenomenológico-hermenéutica. ¿En qué sentido fenomenológica y en cuál hermenéutica? Si comprendemos aquí la relación religiosa en un sentido laxo como relación del hombre con Dios resultante de una respuesta humana a una originaria afección de lo Absoluto, entonces el acceso a dicha relación podrá caracterizarse como fenomenológico si se funda en experiencias universales. En efecto, en tanto fenomenológico tal acceso debe partir de experiencias en las que se muestre y, por ende, se deje describir, la afección de lo Absoluto. Además, en la medida en que la fenomenología abre un acceso filosófico a los fundamentos de la relación religiosa, este acceso debe ser universal esto es, debe ser un acceso transitable por todo hombre qua hombre. De allí que las experiencias de las que parta deban ser experiencias universales, experiencias que no hace un hombre particular por su condición de ser ese hombre o ese grupo de hombres, sino que las tiene o, mejor aún, que le salen al encuentro a todo hombre en tanto hombre. Finalmente la perspectiva fenomenológica aquí adoptada es, además, de carácter hermenéutico, lo que significa que no pretende probar con el rigor de la deducción formal la existencia de Dios ni la verdad de una determinada religión, sino que, de acuerdo con la concepción de la hermenéutica que explicita algo como algo, ella aspira a evaluar en qué medida es legítimo interpretar, esto es, explicitar como de carácter religioso las experiencias en las que se funda.

Para alcanzar los objetivos señalados a partir de los presupuestos metodológicos establecidos considero que se pueden recorrer los tres últimos libros de M. Henry dedicados al cristianismo en función respectivamente de tres cuestiones en las que sale a luz el problema del límite entre pensamiento fenomenológico y pensamiento religioso. Tales cuestiones son la del Archi-hijo en Soy yo la verdad, la de la noción de Archi-carne en Encarnación y la de la legitimación de las palabras que Cristo 
pronuncia sobre sí mismo en Palabras de Cristo. Finalmente, puesto de manifiesto en qué medida estos tres temas de la filosofía henryana superan el marco estrictamente fenomenológico, será necesario volver a la intuición que el filósofo tiene acerca de la esencia de la vida y mostrar también en qué medida ella puede ser comprendida como un acceso fenomenológico genuino a una genuina relación religiosa.

\section{La cuestión del Archi-hijo}

A la verdad del mundo, esto es, al concepto griego de fenómeno para el cual la verdad de una cosa, lo que determina su modo de desocultarse y manifestarse, está dada fuera de sí misma en el mundo, el cristianismo opone la verdad de Dios como vida. "Yo soy el camino, la verdad y la vida" (Juan 14.6) dice el Dios viviente de sí mismo. La vida -dijimos- designa una manifestación pura, incomparable con la del mundo; su revelación es originaria y no depende de nada otro que sí para revelarse, ni se revela a ningún otro que no sea a sí misma. La vida es una revelación de sí a sí, "esta auto-revelación absoluta es precisamente la vida"7. Esta concepción fenomenológica de una vida que se auto-manifiesta nada tiene que ver con las concepciones biológicas. Los procesos físicos y químicos que constituyen la vida biológica se los puede analizar tanto como se quiera que de ellos sólo se extraerán más procesos físicos y químicos, pero jamás la auto-afección, la capacidad de sentirse a sí mismo viviente y, así, manifestarse fenomenológicamente a sí. Por ello puede afirmar Henry "la oposición radical entre la materia fenomenológica de la que está hecha la Vida en tanto que auto-revelación, en tanto que Verdad original, por una parte, y la materia no fenomenológica de los elementos constitutivos de las propiedades químicas o propiamente biológicas, por otra"8. La verdad de la vida fenomenológica (su auto-revelación) es, pues, por completo diferente de la de la biológica. Además es más original, porque los procesos biológicos en sí mismos son ciegos y para devenir objetos de un saber posible deben aparecer iluminados por un logos que los configura, a saber, el logos del mundo en el cual aparecen. Por el contrario, la vida fenomenológica no sólo aparece tal como es en sí misma a sí misma en la afección de sí, sino que es condición del aparecer de la verdad del mundo. En efecto, el hecho mismo de que el mundo aparezca y de que los entes que en él son se muestren supone un viviente que se experimenta a sí mismo experimentando los entes que le salen al encuentro en el mundo. Por ello no es el mundo el "lugar" de la vida, sino la vida el "lugar" del mundo. Sin embargo el hombre, en tanto viviente que se siente a sí mismo y en el cual la vida viene y se experimenta a sí misma, es menos que la vida, porque el hombre se padece a sí mismo, está entregado a la

\footnotetext{
${ }^{7} M V$, p. 47

${ }^{8} M V, p .47$.
} 
condición de ser aquel en el que la vida viene a sí, pero él no puede generar la vida en su acepción fenomenológica. No es el origen de la vida que experimenta. A él la vida le es dada en el mismo acto por el cual se auto-revela como vida en su sentirse a sí mismo del viviente. "En la medida en que la vida es más que el hombre, comprendido en tanto que viviente, es de la Vida y no del hombre, que es necesario partir. De la Vida, es decir, de Dios, en la medida en que, según el cristianismo, la esencia de la Vida y la de Dios son una y la misma esencia"9. Esta declaración de Henry es fundamental, porque ella implica un cambio en la perspectiva, que, como veremos, es lo que supone el abandono del estricto terreno fenomenológico. El análisis, yendo más allá de lo propiamente experimentable, esto es, de la descripción de la materia fenomenológica de la vida en tanto auto-afección de un viviente y de su condición de dada, y, por tanto, del viviente como una ipseidad o "sí mismo" que se padece a sí en tanto viviente, pretende analizar el engendramiento mismo de la Vida en Dios. Cambia el eje del análisis: ya no se describe la relación del viviente con la Vida desde la perspectiva del viviente, sino de la Vida con el viviente desde la perspectiva de la Vida misma10. Henry va más allá de lo estrictamente experimentable por el hombre qua viviente, del cual, por cierto, se puede aseverar que siente el venir de la vida a su sí mismo, y afirma ahora que es necesario comenzar por "el proceso eterno e inmutable" que tiene lugar "en Dios mismo" y en el cual "ella [la Vida] se hace vida"11. Esto último ya es mucho más difícil de legitimar desde el punto de vista fenomenológico y se acerca a la especulación metafísica. En efecto, esta inversión de la perspectiva fuerza a Henry a realizar una distinción. Si aceptamos que el análisis debe partir de la Vida y no del viviente; si la vida y el padecimiento de la vida como un don por el viviente no es el límite del análisis, entonces hay que distinguir en la identidad de la vida consigo misma, en su pura

\footnotetext{
${ }^{9} \mathrm{MV}$, p. 68.

10 Aquí nos separamos decididamente de lecturas de corte netamente teológico, como la de A. Vidalin, quien califica al texto citado, que quiebra con el principio de atenerse a lo dado tal como se da e introduce elementos especulativos, como la expresión de "la llegada de la intuición esencial y nueva de M. Henry" (Vidalin, A., op. cit. p. 80). Más allá del hecho de que el comentarista se limita a reseñar prolijamente las tesis del filósofo y en ningún momento funda el porqué de esta caracterización de "esencial" del nuevo eje del análisis respecto a la visión de la $E M$, lo que resulta cuestionable aquí es la utilización del término "intuición". Si por intuición se entiende una gnosis, una revelación particular propia de un sujeto inspirado, puede aceptarse el uso de la palabra, pero queda cuestionado el carácter filosófico de esta intuición. Si por intuición, en cambio, se quiere decir el conocimiento directo e inmediato de lo que se muestra a todo sujeto tal como se muestra, entonces habría que preguntarse en qué medida se muestra a todo hombre "el proceso eterno e inmutable en el cual Dios se hace Vida". No puedo no sentirme a mí mismo ni no sentir que me ha sido dado este sentir-me a mí mismo, pero no queda claro por qué ello implica necesariamente afirmar que, experimentando-me, "intuyo" el proceso por el que Dios se hace Vida generando en sí la Vida de un primer Viviente. La inversión del análisis parece especular sobre el auto-engendrarse de Dios más que atenerse a un fenómeno y describir una intuición.
}

${ }^{11}$ Cf. $M V$, p. 68. 
inmanencia e idéntica sustancia fenomenológica, dos formas diferentes de una misma cosa. En primer lugar está la Vida absoluta, que es capaz de generase a sí misma, y que el cristianismo llama Dios. En este primer caso la relación de la vida al viviente "se juega en el interior de Dios mismo"12 y "se produce como generación del Primer Viviente en el seno de la autogeneración de la Vida"13. A este Primer Viviente, en el que la Vida absoluta se siente a sí misma como auto-engendradora de sí, Henry lo califica de "Hijo primo-génito y único", lo denomina "Archi-Hijo" trascendental de la Vida y, finalmente, a este único lo identifica llanamente con Cristo. En segundo lugar está la vida trascendental humana, la auto-afección que no puede generarse a sí misma y que es la vida de aquellos que el cristianismo llama hijos de Dios. En este segundo caso la relación de la Vida al viviente (y aquí las siguientes palabras de Henry confirman el abandono del plano de las experiencias estrictamente humanas en la primera significación de la Vida para pasar al sorprendente análisis "fenomenológico" de lo que ocurre dentro de Dios mismo) "no concierne más a la relación de Dios consigo mismo, sino a su relación con el hombre, ella [la Vida] se produce como generación del hombre trascendental en el seno de la autogeneración de Dios"14. Este desdoblamiento de la vida que es experiencia de sí, pura auto-afección, en la Vida del Archi-Hijo y la vida de los hijos, lo lleva a Henry a una paralela distinción en la noción de auto-afección, del sentir-se a sí misma viniendo a sí, que caracterizaba en la Esencia de la manifestación la materia fenomenológica patética única de la vida. Por un lado estaría la autoafección en sentido fuerte y por otro la auto-afección en sentido débil. Según el concepto fuerte "la vida está afectada por un contenido que es ella misma y, además, es ella quien pone este contenido por el cual es afectada - es ella quien afecta, quien se afecta. Este concepto fuerte de auto-afección es el de la vida fenomenológica absoluta y no conviene más que a ella, es decir, a Dios"15. Según este concepto fuerte, entonces, la vida absoluta tiene la potencialidad de darse su propia vida -el poder vivir- y el contenido, esto es, la tonalidad patética según la cual se siente a sí misma. Según el concepto débil yo me experimento a mí mismo, experimento el contenido patético de mi propia vida, que es mi sí mismo viviente, como lo experimenta la Vida absoluta, pero yo no me doy a mí mismo esa vida que experimento como la mía, sino que me es dada. Escribe Henry: "Soy yo quien está afectado y lo estoy por mí mismo en el sentido que el contenido que me afecta soy todavía yo mismo -y no algo otro (...). Pero esta auto-afección que define mi esencia no es mi hecho. Es así que yo no me afecto absolutamente, sino que, para decirlo rigurosamente, yo soy y yo me encuentro auto-afectado"16. Este concepto débil de auto-

\footnotetext{
$12 M V, p .68$.

$13 M V$, p. 69.

$14 M V$, p. 69 (cursivas mías).

15 MV, p. 135.

$16 M V$, p. 136.
} 
afección, esta capacidad de experimentar la propia vida pero no de darse a sí mismo la capacidad de experimentar la propia vida es el que corresponde a la esencia del hombre, no de Dios. El sí es pasivo respecto al engendramiento de su propia vida. Dios es activo. ¿Cuál es la relación entre estos dos modos de auto-afección? ¿Cómo el sentido débil de la auto-afección se funda en el fuerte? Henry responde: "En el hecho de que el sí singular que yo soy sólo se experimenta a sí mismo en el interior del movimiento por el cual la Vida se arroja en sí y goza de sí en el proceso eterno de su auto-afección absoluta." 17 La conclusión que de esta relación de fundación extrae Henry es clara: "El Sí sólo se auto-afecta en la medida en que se auto-afecta en él la Vida absoluta"18. Podemos aquí, siempre que aceptemos la definición henryana de vida, suscribir la tesis de que sólo puedo experimentarme como viviente si en mi experiencia lo que Henry llama Vida absoluta de algún modo me afecta dándome mi propia vida. Empero no se ve la necesidad fenomenológica de introducir, como lo hace Henry, la intermediación de un tercer término: el Archi-Hijo, para explicar la relación de la Vida con los vivientes. ¿En qué consiste el rol de este intermediario? El Archi-Hijo -recordemos- es generado en el proceso de auto-afección de la Vida absoluta. Cristo copertenece a este proceso en tanto él es el Primer Viviente, la Ipseidad esencial en la que la Vida viene a sí misma. De acuerdo con ello debemos distinguir en Herny tres relaciones correspondientes a tres necesidades trascendentales. La primera radica en el hecho de que la Vida absoluta engendra la vida del viviente para que éste pueda auto-experimentarse. A esta primera necesidad fundamental se agrega una segunda relación trascendental, a saber, el nacimiento de un Primer Viviente, en que la Vida viene a sí misma. Y finalmente una tercera: la circunstancia de que la relación del sí-mismo trascendental a Dios no es directa, sino precisamente mediada por el Primer Viviente. De allí que esta tercera relación se exprese afirmando que el hombre sólo es hijo de Dios en en Archihijo: "Hijo en el Hijo"19. A pesar de su intención de fundamentar esta última necesidades trascendental la explicación de Henry se reduce a lo siguiente: ningún viviente es posible sin la Vida, y como la esencia de la Vida es venir a sí en un Primer Viviente, ningún viviente es posible salvo en la Ipseidad de la Vida. Por lo tanto ningún viviente es concebible sin el Primer Viviente, el Archi-Hijo, Cristo. "Que ningún viviente sea posible si no es en la vida, quiere decir, entonces, que él es posible en el Archi-Hijo y solamente en él." 20

De cara a estas tres necesidades trascendentales que se distinguen en el pensamiento de Henry surgen para una lectura fenomenológica inevitablemente algunas cuestiones. Quisiera aquí plantear tres. En primer lugar, la introducción de una tras-

\footnotetext{
$17 M V$, p. 136.

$18 M V$, p. 136.

19 MV, p. 139.

$20 M V$, p. 139.
} 
cendencia en la inmanencia. En segundo, la introducción de un mediador con esa trascendencia. En tercero, la especificidad de la mediación. Tomemos la primera cuestión. ¿Más allá de la distinción entre auto-afección fuerte y débil no es menester reconocer una cierta trascendencia ${ }^{21}$, aunque no fuese extática, de la Vida absoluta, en tanto engendradora, respecto de la vida humana, que no puede engendrase a sí misma? ¿No constituye ello un problema para una filosofía que reclama para sus análisis fenomenológicos de la vida el estatus de una inmanencia radical y de una identidad en la sustancia fenomenológica de la vida? Si hay una diferencia, paralela a esta trascendencia en la inmanencia, entre la Vida absoluta auto-engendrada y la humana engendrada $-\mathrm{y}$ no es una diferencia tan pequeña, puesto que es la diferencia que determina que uno sea Dios y otro hombre- ¿cómo es posible afirmar que en nuestra experiencia de la vida la propia Vida se experimenta a sí misma o "se arroja a sí"? ¿En tal sentido no hubiera sido fenomenológicamente pertinente limitarse a la explicitación de la experiencia de la propia vida como dada, sin querer avanzar en el modo en que se experimenta a sí la Vida absoluta? Lo cierto es que la introducción de una trascendencia en la filosofía del cristianismo de Henry, aunque distinta de la trascendencia del Dios hebraico y aunque experimentada en la inmanencia, complica la concepción fenomenológica de la vida de La esencia de la manifestación. La experiencia de sí ya no es su propio fundamento fenomenológico, sino que ahora está subordinada a un Archi-fundamento, a la afección en sentido fuerte de la Vida en el Primer Viviente, puesto que los hijos sólo pueden serlo en el hijo ${ }^{22}$. Pasamos así a la segunda cuestión: la del intermediario entre la Vida absoluta y la vida humana. Si la Vida, una y la misma, se engendra en los vivientes y en cada uno experimenta una modalidad o tonalidad específica, entonces cuál es la necesidad trascendental de introducir un Primer Viviente y cuál el estatus fenome-

${ }^{21}$ El propio Henry reconoce una cierta evolución de la fenomenología material que en sus últimas expresiones dedicadas al cristianismo introduce una cierta trascendencia interna a la inmanencia. Así, por ejemplo: "En la fenomenología material] hay una trascendencia en sentido tradicional, pero esta trascendencia no es del todo extática, ella es la relación, impensada hasta el presente, del viviente a la vida, que se puede leer como la experiencia que el viviente hace de la vida, la cual es, en el fondo, la experiencia que hacen todos los místicos y que todos los hombres viven sin saberlo" Henry, M.: "Art et phénoménologie de la vie. Entretien avec Michel Henry", en: Prétentaine, 6, 1996, pp. 129-141. En $M V$ también Henry reconoce que esta disociación entre los hijos de la vida, por una parte, y el ArchiHijo y la Vida absoluta, por otra, "fait problème". Cf. $M V$, p. 135.

22 Coincido por completo aquí con S. Laoureux quien ha observado que la introducción de esta trascendencia en la inmanencia como fundamento de la experiencia del ego nos permite atisbar una forma sui generis de la metafísica ontoteológica clásica que el propio Henry rechaza. En efecto, se pregunta el intérprete, con la introducción de esta trascendencia en la inmanencia y de la figura del Archi-fundamento "¿no se ve Dios en el pensamiento henryano remitido a su rol fundador en la arquitectura de la metafísica clásica?" Y agrega: ¿Instituyendo un tal fundamento, la fenomenología henryana no desvía su problemática en un más allá de la fenomenalidad? ¿Cuál es, en otros términos, la fenomenalidad de este Archi-fundamento?" Laoureux, S.: L'inmanence à la limite. Recherches sur la phénoménologie de Michel Henry, París, Éditions du Cerf, 2005, p. 205. 
nológico de este intermediario? ¿Cómo, si no es a partir de una experiencia mística, propia de ciertos elegidos, es posible afirmar que la experiencia de sí, que es precisamente eso, experiencia de sí, es ya una experiencia en el Archi-Hijo? ¿Por qué para experimentarme a mí mismo -experiencia propia de todo viviente y que no es posible no tener-; y para experimentar incluso que la vida me es dada, necesito experimentar que me es dada en un Primer viviente? Y, además, ¿cuál es la legitimidad fenomenológica, en el estricto sentido que le dimos a esta palabra en la introducción, de afirmar-abandonando la perspectiva de los vivientes y pasando a la perspectiva de la Vida- que ésta, para sentirse a sí misma, tiene que engendrar no sólo vivientes, sino un Primer Viviente? Y pasemos ahora a la tercera cuestión: ¿Por qué ese Viviente único sólo puede ser Jesus, el Cristo neotestamentario? Estas preguntas no encuentran una respuesta unívoca y clara en el contexto de C'est moi. La verité. Quizá sea posible legitimar la primera relación trascendental que se puede leer en Henry, a saber, postulación de una Vida Absoluta como fuente de la vida del individuo a través de una explicitación hermenéutica de la experiencia de mi vida como dada, pero la disolución del individuo en esa Vida absoluta y la fusión de la experiencia de su vida con la experiencia que la Vida absoluta tiene de sí, tiene sentido en términos místicos o especulativos, pero no parece sostenible desde el punto de vista fenomenológico. La segunda relación y la segunda tesis que plantea Henry, a saber, que la Vida se engendra en un Primer Viviente nuevamente es de carácter especulativo, no fenomenológico. ¿No implica tal afirmación la pretensión de determinar la mismísima experiencia de Sí de la Vida Absoluta? Por otro lado, ¿cuál es la experiencia que tenemos de ese Primer Viviente? Y si no podemos tener experiencia de ese Hijo Unigénito, ¿cómo es entonces posible afirmarlo como fundamento fenomenal de nuestra propia vida? Tales preguntas muestran que, introduciendo este intermediario como fundamento de la experiencia de sí de cada viviente, Henry introduce a la vez en la esencia última de toda manifestación, que es la experiencia de sí, un fundamento no fenomenal o, por lo menos, un fundamento cuya fenomenalidad es altamente cuestionable. Finalmente la tercera tesis henryana, que identifica al Primer Viviente con Cristo y afirma que sólo en Cristo son posibles los sí trascendentales en tanto "hijos en el Hijo" sólo puede ser inteligible desde una perspectiva confesional, como si Henry utilizase y adaptase su fenomenología de la vida para elucidar su propia experiencia y fe religiosa. El punto clave aquí para entender aquello que ocasiona estas preguntas dirigidas al pensamiento de Henry es tener en cuenta que su filosofía del cristianismo desde C'est moi la verité y de modo creciente hasta llegar a Palabras de Cristo invierte la perspectiva fenomenológica de análisis de la relación religiosa. Ya no se trata de abrir un acceso a la cuestión de Dios a partir de la explicitación hermenéutica de fenómenos experimentables por todo hombre en tanto que tal, pero que remiten a una instancia no explicable ni contenible por la verdad del mundo, como podría ser la auto-experiencia patética de la 
vida en su carácter de dación, sino que ahora de lo que se trata es, desde la perspectiva de la Vida misma, explicar su proceso de auto-engendramiento. Dicho de otro modo, de lo que se trata ahora ya no es de pensar la interpelación del sujeto por algo Absoluto desde la afección que esa interpelación pro-voca, sino de determinar la interpelación misma desde su fuente primera. Allí la fenomenología vira -si no a la teología 23 - al menos hacia la metafísica especulativa.

\section{La cuestión de la "Archi-carne"}

En su segundo libro destinado a la interpretación fenomenológica del cristianismo, esto es, en Encarnación, Henry, a mi modo de ver, lleva adelante un verdadero avance fenomenológico en la determinación del modo en que la vida viene a sí con la explicitación de la noción de carne y su diferencia con el cuerpo puramente físico. El filósofo comienza distinguiendo el cuerpo humano, que se experimenta a sí mismo al mismo tiempo que siente lo que lo rodea, de los cuerpos inertes del universo que no sienten nada. "Llamaremos carne al primero, reservando el uso de la palabra cuerpo para el segundo. Esto es así porque nuestra carne no es otra cosa que aquello que, al experimentarse, sufrirse, padecerse y soportarse a si mismo y, de este modo, gozar de sí según impresiones siempre renacientes, es susceptible, por esta razón, de sentir el cuerpo exterior a sí, de tocar así como de ser tocado por él."24 Esta definición de carne nos permite extraer de modo inmediato dos conclusiones. Primero: aquello concreto en que el hombre se experimenta a sí y la vida viene a sí misma es su propio cuerpo, pero no en tanto cuerpo material objetivo, sino en tanto cuerpo tocado y tocante, esto es, en tanto carne. Como carne el cuerpo del hombre se distingue de todo cuerpo objetivo por estar transido de una impresividad patética, es decir, por ser susceptible de padecer-se y, por tanto, de padecer el modo en que lo afectan las impresiones constantemente renacientes de todo lo que lo rodea. La carne es, pues, lo "invisible" en el cuerpo: su impresividad. Segundo: no es el estudio del cuerpo objetivo el que nos permitirá conocer nuestra carne, porque ningún cuerpo inerte se siente a sí ni por ende es impresionado por nada, sino el hecho de que nuestra carne, en el seno de su propio pathos de sí, pueda ser impresionada

\footnotetext{
23 Este viraje teológico del pensamiento de Henry fue observado también entre otros con mucha claridad por D. Janicaud "La teologización de la fenomenología deviene aquí literal, puesto que ella es visión de Dios en Dios, pero sin que se haya justificado ni de que fenomenalidad se trata a este nivel ni a titulo de qué se debe admitir como fenomenológicamente evidente una concepción trinitaria de la vida divina, de la que -después de todo- la iglesia católica ha debido hacer un dogma." Janicaud, D.: La Phénoménologie éclatée, París, L'éclat, 1998, p. 15. De mi parte reduzco aquí la teologización a la introducción del "Archi" y no a la apertura de un acceso fenomenológico a la cuestión de Dios a partir de la experiencia de la vida como un absoluto inderivable del mundo y, sin embargo, dado.

${ }^{24} I$, p. 10 (cursivas del autor).
} 
por los cuerpos objetivos es la condición de posibilidad del conocimiento de cualquier cuerpo objetivo 25 . A partir de esta comprensión originaria de la carne, el filósofo se pregunta, y lo hace desde el punto de vista filosófico, al que afirma estrictamente atenerse, ${ }^{26}$ lo siguiente: “¿Es posible alguien como Cristo? ¿Es concebible por lo menos el devenir hombre de Dios en cuanto devenir carne del Verbo?"27 Esta pregunta implica no sólo la pregunta por una simple posibilidad lógica, sino la pregunta por la realidad efectiva, esto es, por la mostración y la consecuente experiencia efectiva de Cristo en tanto Verbo de Dios hecho carne. La pregunta podría también formularse en estos términos: ¿"Cómo la existencia de Aquél que es uno y el mismo en calidad de Verbo y en calidad de carne es susceptible de advenir a nosotros, de darse realmente, de mostrársenos?"28 ¿Cómo habrá, pues, que considerar la carne para que en ella misma se cumpla la revelación del Verbo? ¿Y cómo habrá que pensar la revelación para que ella se cumpla en y por la carne? Para responder a estas preguntas Henry parte de la siguiente sospecha: si la venida a una carne -la encarnación- fue, según lo comprendieron los primeros pensadores cristianos, el modo de manifestación del Verbo de Dios, entonces "ese modo de manifestación de la carne y el del Verbo podrían muy bien, en calidad de modos de manifestación y revelación de la Vida, ser los mismos"29. Dicho de otro modo: si la Vida sólo puede ser tal experimentándose en un viviente, y si, como nuestra propia experiencia nos lo indica, experimentarse es experimentarse en una carne, entonces bien podría ser que el venir a la vida de la Vida, el mostrarse, el revelarse en un Primer Viviente equivalga a su encarnación. Ahora bien, es necesaria una elucidación sistemática de esta revelación. Tal elucidación la ofrece, para Henry, la fenomenología, pero no la fenomenología entendida al modo heideggeriano como la pregunta por la aparición del ser en el horizonte del mundo (tal fenomenología sólo podría ocuparse del cuerpo y no de la carne), sino una fenomenología mucho más originaria: la de la vida. ¿Cómo, pues, responde filosóficamente la fenomenología de la vida a partir de la sospecha consignada más arriba a la pregunta por la mostración y la consecuente experiencia efectiva de la encarnación en Cristo de la Vida absoluta, del Verbo, cuya acción como Verbo es dar vida?

Para poder responder esta pregunta hay que partir del hecho de que la auto-revelación de la vida y la experiencia de la propia carne son un mismo fenómeno. La sustancia fenomenológica de la vida y la de la carne son una misma cosa. La carne

\footnotetext{
25 "Lejos, pues, de que el análisis del cuerpo pueda convertirse en el de nuestra carne y en el principio, un día, de su explicación; la verdad es totalmente otra: sólo nuestra carne nos permite conocer, en los límites prescritos por este cuerpo ineludible, algo así como un 'cuerpo" I., p. 12 (cursivas del autor).

26 Cf. I, p. 24.

$27 I$, p. 24.

$28 I$, p. 24.

29 I, p. 24.
} 
es siempre "una carne impresiva y afectiva cuya impresividad y afectividad no provienen nunca de algo distinto a la impresividad y a la afectividad de la vida misma" 30 . De allí que no tenga sentido para el hombre comprendido como viviente hablar de un dualismo entre cuerpo y alma, pues no hay otra alma que la vida que se experimenta en la carne. El hombre en tanto sí mismo trascendental en un Sí unitario porque la carne es la realidad concreta de nuestro experimentarnos como sí mismos. "Yo [Moi] y Carne son una sola cosa"31. Y si lo son es porque el uno y la otra no son más que la manifestación de la esencia fenomenológica (en cuanto experimentable) y originaria (en cuanto no se derivan ni suponen nada otro) según la cual "la vida viene a sí y se encuentra siendo la vida"32. La carne es la forma que tiene la Vida de hacerse vida. Sin embargo -y aquí introduce Henry una declaración sorprendente para el punto de vista estrictamente filosófico del análisis- "esta conexión originaria y esta reciprocidad, esta interioridad recíproca de la Carne y de la Vida, sólo atañe a una vida como la nuestra porque, antes del tiempo, antes de todo mundo, se ha establecido en la Vida absoluta como el modo fenomenológico según el cual esta Vida viene eternamente a sí en el Archi-Pathos de su Archi-Carne"33. Henry llama Archi-pasibilidad a aquello que da la posibilidad de experimentarse a sí mismo, esto es, de experimentar la propia carne, y que lo hace desde antes del mundo y del tiempo, de modo completamente a priori. Tal Archi-pasibilidad la encuentra en el Archi-Pathos de una Archi-Carne. Y concluye: "vemos muy claramente que esta Archi-pasibilidad pertenece a la Vida absoluta como su misma 'naturaleza', como la materia fenomenológica en la que se cumple su venida originaria a sí misma." 34 Ahora bien, ¿en qué se funda esta evidencia? ¿Sobre qué bases fenomenológicas puede Henry aquí nuevamente invertir la perspectiva originaria de análisis, que iba de la experiencia de una carne, a la que le está dada experimentar pasivamente su propia vida en su impresividad patética, y pasar a describir ahora lo que se "ha establecido en la Vida absoluta antes del tiempo y del mundo"? ¿Cómo es posible llamar fenomenológica a la "experiencia apriorística" de la ArchiPasibilidad propia de la Archi-Carne? ¿Si mi carne es la misma que la Archi-Carne, si nuestra carne es "la carne en la que el Verbo de la Vida se hace idéntico a cada uno de los vivientes que somos nosotros" 35 , entonces qué necesidad hay de introducir una Archi-Carne? Y, si, por el contrario, es distinta, en cuanto ella se da a sí misma su Archi-Pasibilidad, ¿cómo puede el hombre experimentar esa ArchiPasibilidad de la Archi-Carne en la suya propia? Todos estos interrogantes son ine-

\footnotetext{
30 I, p. 159.

31 I, p. 163.

$32 I$, p. 163.

33 I, p. 160 (cursivas mías).

${ }^{34} I$, p. 160 (cursivas mías).

35 I., p. 28.
} 
vitables y sobre las cuestiones que ellos refieren se cierne la sospecha de la especulación. Dicha sospecha surge, nuevamente, a causa de la inversión de la perspectiva de análisis que cumple la fenomenología de la vida devenida fenomenología del cristianismo o, mejor aún, fenomenología cristiana. La única fundamentación filosófica que de la "evidencia" de la Archi-Carne ofrece Henry en su análisis de la encarnación pasa por aceptar el supuesto del Archi-Hijo, esto es, no por aceptar el principio fenomenológico de que no hay vida sin un viviente, sino la idea altamente especulativa de que ello implica necesariamente que la Vida Absoluta se autoengendra en un único Primer Viviente, que es Cristo. A esta idea la denomina Henry "primer ley de la Vida" y la deriva de la "Archi-inteligibilidad joánica"36. Si aceptamos esta primer ley de la Vida, entonces es fácil hacer un paralelismo y "argumentar", como lo hace Henry, que si, en primer lugar, la Vida absoluta se engendra en un Primer Viviente y cada sí trascendental humano es engendrado en ese Primer Viviente que es el Archi-Hijo, y si, en segundo lugar, aquello en lo que concretamente viene a sí la Vida, la materia de su auto-revelación, es la carne, entonces necesariamente mi carne es engendrada en la Archi-Carne del Archi-Hijo ${ }^{37}$. Ahora bien, los presupuestos de los que parte esta argumentación, que pretende ser fenomenológica y conducir, por tanto, a todo hombre a una evidencia, a saber, la primera ley de la Vida absoluta y el consecuente concepto de Archi-Hijo, distan mucho de constituir una experiencia fenomenológica de carácter necesario y universal. Tal argumentación transfiere, por tanto, a la Archi-Carne, postulada paralelamente al Archi-Hijo, todos los problemas y cuestionamientos ya expresados en relación con este último. Nuevamente lo que se extraña en Henry, a pesar de su pretensión de mantenerse en el plano estrictamente fenomenológico, es la fundamentación, precisamente fenomenológica (esto es, la remisión a fenómenos que se muestran en sí y por sí mismos y que son en tanto tal correlato de una experiencia posible para cualquier sujeto) del pasaje de la experiencia de la carne como materia fenomenológica de la revelación de la vida a sí misma a la idea de que el sujeto experimenta su vida y, por ende, su carne en la Archi-Pasibilidad y en la Archi-Carne del Archi-Hijo. Hubiera sido tal vez más consecuente afirmar, como se lo confiesa abiertamente en las palabras que cierran el libro, que el conocimiento de que nuestra carne está "dada a sí en la Archi-Pasibilidad de la Vida absoluta", de que ella en su pathos es la "Parusía del absoluto" y, finalmente, de que, "en el fondo de su Noche, nuestra

\footnotetext{
36 Cf., I. p. 29

37 Henry realiza expresamente este paralelismo como fundamentación de la mostración de la ArchiCarne: "Esta nueva evidencia golpea entonces nuestra mirada. La generación de nuestra carne es estrictamente paralela a la de nuestro Sí trascendental, que hace de nosotros en cada caso este 'yo' [moi] o este 'ego' que somos. O mejor, se trata aquí de una sola y la misma generación. La generación del viviente en la Vida es la de nuestro Sí trascendental en el Archi-Sí de la Vida absoluta -en su Verbo-y, de igual modo, la de nuestra propia carne en la Archi-Carne de ese Verbo." I, pp. 162-163 (cursivas mías).
} 
carne es Dios" 38 resultan no de un análisis fenomenológico, sino de la "Archi-gnosis" que es "la gnosis de los simples". 39 Si esto es así, entonces el acceso fenomenológico a la relación religiosa, abierto en principio a todo hombre en la experiencia de que la propia carne, como materia de la auto-revelación que todo viviente tiene de su vida, nos ha sido dada, queda ahora reducido a los simples capaces de una Archi-gnosis ${ }^{40}$.

\section{La cuestión de la legitimación de las palabras de Cristo sobre sí mismo}

Cualquier análisis del último libro de M. Henry: Palabras de Cristo debe considerar que en él la pretensión de mantenerse dentro de límites exclusivamente filosóficos es definitivamente abandonada. A diferencia de los anteriores, que llevaban como subtítulo respectivamente "Para una filosofía del cristianismo" y "Una filosofía de la carne", el título es expuesto aquí en su cruda desnudez: Palabras de Cristo.

\footnotetext{
38 Cf. $I$, p. 338.
}

39 I, p. 339.

40 Naturalmente nuestra interpretación está en las antípodas de la de, por ejemplo, X. Tilliete. En lugar de una inversión en el plano del análisis de la relación del viviente con la Vida que se transforma en la filosofía del cristianismo en la relación de la Vida consigo misma y de un consecuente salto especulativo, Tilliete (ciertamente sin fundamentar por qué) asevera que hay "una especie de ósmosis que se produce entre el mensaje inmemorial y sagrado y la exigente reflexión del filósofo." Tilliette X : "La christologie philosophique de M. Henry" en David A. y Greisch J. (eds.), Michel Henry, la épreuve de la vie. Actes du colloque de Cerisy 1996, París, Les Éditions du Cerf, 2001, pp. 171-180, aquí, p. 177. Inclusive el estudioso lamenta que las virtualidades de esta filosofía no hayan sido suficientemente explotadas en perspectiva cristiana. Tilliette reclama para la interpretación del cristianismo de Henry el título de filosófica y, para mí de modo sorprendente, funda este reclamo en el hecho de que el proyecto henryano de "escrutar el ser y la esencia (la verdad) de Cristo se asienta en el vector indispensable de toda cristología filosófica, a saber, la Idea Christi, en este caso bajo el aspecto del Hijo por excelencia, del Primer Nacido." (Ibid. p. 172). Y Tilliette redobla la apuesta: "Por ello la legitimidad de una cristología que quiere presentarse como filosófica es todavía una vez más demostrada, (...), pues la inteligencia de Cristo se apropia y sujeta los términos y los significantes de la filosofía." (Ibid. p. 172). Naturalmente, si la idea de Cristo como Primer Nacido no sólo es aceptada como una idea de carácter filosófico, sino como aquello que funda la pretensión de ser filosófica de una filosofía, no puede resultar raro que el comentarista extrañe una mayor cristianización aún de la filosofía henryana, y le parezca que hay "virtualidades no suficientemente explotadas". Así a Tilliette le sabe a poco la comprensión del filósofo de la encarnación, lamenta incluso "un cierto déficit de encarnación" (ibid., p. 178) resultante de un exceso de inmanencia. En esta línea hubiera sido deseable legitimar filosóficamente no sólo la encarnación del Verbo en una Archi-Carne invisible, sino la salvación "por sus trabajos y por su muerte, no solamente por la Revelación de su Persona y de la condición de Hijo" (ibid). Cómo se le puede criticar desde un punto de vista filosófico a Henry que en su filosofía no tengan lugar la resurrección concreta de Cristo o "la cruz, la muerte ignominiosa, la meditación del viernes santo y del sábado santo" (ibid., p. 180) es algo que me resulta tan poco comprensible como la afirmación del crítico de que M. Henry ha respetado fielmente los límites filosóficos de su cristología porque "ha adoptado plenamente las afirmaciones de la fe." (Ibid. p. 180). 
Ese mismo hecho es una señal de que el libro ya no ha de proceder siguiendo una estricta metodología fenomenológico-trascendental, progresando de las evidencias a sus implicaciones. De lo que se trata ahora es simplemente de escuchar y comprender las palabras de Cristo; tanto aquellas que, considerado como hombre y en el lenguaje de los hombres, les ha dicho sobre ellos mismos, cuanto aquellas en las que, también como hombre y en el lenguaje humano, les ha dicho de sí mismo. Sin embargo la perspectiva filosófica no es del todo abandonada, no sólo por el hecho de que Henry aborde la cuestión de la diferencia entre la palabra de Cristo como Verbo de Dios y la palabra humana, ni la consecuente cuestión de cómo los hombres son capaces de oír y comprender la Palabra divina, sino sobre todo porque, a lo largo del texto, una y otra vez se pregunta Henry por la legitimación de las palabras que Cristo pronuncia sobre sí mismo; asunto en el que centraremos aquí nuestra atención.

La afirmación de Cristo de su condición divina ilumina el conjunto del evangelio de Juan y culmina con su identificación con el Verbo de Dios hecho hombre (Juan 1. 14). Pero ya en los sinópticos él se revela como el Hijo en una relación única al Padre, que es propiamente una identificación: "quien me recibe a mí recibe a quien me envió" (Mt 10. 40). La cuestión de la afirmación de la identidad divina de Cristo está igualmente presente en el centro del proceso en su contra y será el motivo de su condenación. Al sumo sacerdote que lo interpela diciéndole: "Te juro por Dios vivo; dinos si tú eres el Mesías el Hijo de Dios. Jesús le respondió: Tú lo has dicho" (Mt 26, 63-64). Esta identificación fue la blasfemia que a ojos del Sanedrín merecía la condena a muerte. En términos del propio Henry: "En el conjunto de las palabras que Cristo pronuncia sobre sí mismo, la declaración en la que afirma que es Cristo, es decir, el Mesías, marca el punto culminante. (...). La identificación de Jesús con Cristo y con el Mesías es su identificación con el Hijo de Dios, y su identificación con el Hijo de Dios es su identificación con Dios mismo." 41 Ahora bien, la cuestión que al respecto se plantea el filósofo no puede ser otra que la siguiente: "Más allá de su afirmación, por muy categórica que ésta sea, ¿está Cristo en condiciones de legitimarla? Con otras palabras: ¿es creíble la palabra que dirige a los hombres a propósito de sí mismo y en la que se designa como Cristo y salvador del mundo?" 42 De cara a semejante pregunta Henry comienza negando que el testimonio dado por otros hombres, por muy importante que éste fuese, como el caso del de Juan el Bautista, pueda ser la fuente última de legitimación de las palabras de Cristo. El propio Cristo así lo establece: "Pero yo no dependo del testimonio de ningún hombre" (Jn 5. 34). Y ello porque el testimonio humano se inserta en lo que Henry llama verdad del mundo. En la verdad del mundo lo dicho se refiere a algo distinto de sí, de allí la posibilidad de la mentira y el fingi-

\footnotetext{
$41 P C$, p. 85.
}

$42 P C$, p. 86. 
miento. Es el caso de los hipócritas, que oran de pie en las sinagogas para que la gente los vea, pero que, en su "corazón", esto es, en su experiencia de sí, en realidad no están orando ni creen en el poder de la oración. "La oposición -señala Henry- entre la realidad, que se mantiene en el 'corazón', y la apariencia, que es la del mundo, funda la posibilidad misma de la hipocresía"43. El acto de dar testimonio, como el de orar, considerado según su apariencia en la exterioridad del mundo, porta consigo la posibilidad de la mentira. Podemos dar testimonio de algo que en realidad no experimentamos. En consecuencia, sólo Cristo y el Padre que lo ha enviado, con el cual no es sino uno, pueden dar testimonio de su condición divina. Esta última declaración es concomitante con la siguiente: ninguna palabra humana, ninguna palabra del mundo, que designe o refiera algo distinto de sí, a saber, lo que se muestra en el horizonte del mundo, que es el medio de su manifestación, puede dar testimonio de aquel que, en tanto Vida, no es literalmente de este mundo. A diferencia de la Palabra de la Vida, del Verbo que es y genera la carne de Cristo en la que se encarna, la palabra del mundo, por su carácter referencial, no es la realidad que ella designa ni puede generarla ${ }^{44}$. En consecuencia, sólo la palabra de Vida, que no puede mentir, porquen no es una palabra sobre la vida, sino el auto-engendramiento y la auto-revelación de la vida a sí, puede dar testimonio de la condición de aquel que afirma ser la Vida.

¿Mas en qué sentido la vida es una palabra? Este punto debe quedar claro: la vida es una palabra en la medida en que nuestra vida como experiencia patética de nuestra propia carne viviente, como el efectivo sentirnos afectados de modo inmanente por nosotros mismos, revela o dice esa misma vida. Nuestra vida, en modos tales como el gozo o el sufrimiento, es palabra, pues se dice a sí misma. Ahora bien, si la vida es palabra que se dice a sí misma en el padecimiento patético del propio sí, entonces, la Vida absoluta, que se genera a sí misma, es Verbo que se engendra a sí mismo y se experimenta a sí mismo en la carne de su propio Sí. Henry concluye: "Esta es la razón por la que la Ipseidad en la que ella se experimenta [Cristo] es también una Ipseidad efectiva real: un Sí real, el Primer Sí Viviente, en el que la Vida absoluta se experimenta efectivamente y se revela a sí. Al cumplirse en él esta auto-revelación, este primer Sí viviente es su Verbo, su Palabra. Así es como la autogeneración eterna de la Vida genera en ella su Verbo, el 'Hijo único primogénito' en el que ella se experimenta y se ama eternamente a sí misma." 45 Este sería el fundamento último que legitima las palabras de Cristo sobre sí mismo: el hecho de que Cristo se revela a sí mismo como el Primer Viviente en el que la Vida absoluta dice lo que ella es. Mas una afirmación tal equivale a decir que la legitimación de las Palabras de Cristo sobre sí radica en la propia experiencia que Cristo tiene de

\footnotetext{
43 PC, p. 32.

44 Cf. $P C$, pp. 106-107.

45 PC, p. 120.
} 
sí. Cristo se auto-legitima en cuanto se sabe a sí mismo en su carne la Ipseidad en la que la Vida viene a sí y se hace Verbo. De este modo, la justificación de las palabras de Cristo sobre sí, además de arrastrar todas las dudas que ya elucidamos al tratar la cuestión del Primer Viviento o Archi-Hijo, deviene, para una perspectiva filosófica, perfectamente circular: la razón por la cual Cristo puede decir que es Dios es porque él se experimenta a sí mismo como Dios, es decir, porque es (la experiencia de sí es el ser o esencia de la vida) Dios. Y como en el caso de la palabra de la Vida reina la identidad entre el ser y el decir, esto también podría formularse del siguiente modo: "la razón por la cual Cristo puede decir que es Dios es porque dice que es Dios". Tal circularidad de la argumentación se vuelve particularmente notoria e inaceptable para un pensamiento no confesional cuando Henry, en la conclusión del libro, afirma: "No porque Cristo diga, (...), 'yo estoy con el Padre y el Padre está en mí', ya por ello esta proposición es verdadera en el dominio de la realidad absoluta de Dios. Muy por el contrario: sólo porque él está así en la realidad absoluta de la esencia divina, eternamente así, (...) es por lo que esta Palabra, Archi-revelación de la vida divina, es en sí Verdad (...)"46. La Palabra de Cristo se legitima, entonces, aquí por el hecho de que él es quién dice ser, lo cual no constituye ninguna fundamentación ni evidencia filosófica, puesto que justamente se presupone la verdad de lo que debería evidenciarse. Tampoco y mucho menos aún queda claro cómo es posible a un pensamiento fenomenológico, con la restricción a la evidencia que ello implica, volver a invertir el análisis, que ya no se limita a la descripción de la experiencia de la vida en el viviente, sino que pasa a colocarse en el propio plano de la Vida absoluta, y pretende afirmar qué o quién es lo que está o no está "en la realidad absoluta de la esencia divina"47. De algún modo Henry reconoce esta circularidad cuando afirma que la red de implicaciones que componen el discurso de Jesús sobre sí mismo "conducen a la definición por Cristo de aquel que él mismo es."48 Pareciera ser que esta legitimación circular no conforma del todo al propio Henry filósofo, puesto que el capítulo titulado "El Verbo de Dios. Autojustificación de las palabras pronunciadas por Cristo sobre sí mismo" vuelve a terminar con la pregunta que pretendía responder: “¿Cómo saber, nosotros que no somos Cristo, que Cristo es el Verbo y que sus palabras son las de la Verdad?"49

Otro indicio del carácter altamente cuestionable de la legitimación se manifiesta en el hecho de que al final de la obra, para legitimar las palabras de Cristo y su

\footnotetext{
46 PC, p. 161.

47 Tampoco es aceptable y no sé cómo podría fundamentarse fenomenológicamente la pretensión de imponerle a priori una limitación a la expresión de lo Absoluto y aseverar que la auto-revelación de la Vida en su Verbo divino se ha producido sólo "dos veces en la historia". "Ha hablado por los profetas antes de transformarnos en el momento en que dicha Palabra se ha hecho la de Cristo." $P C$, p. 166.

48 PC., p. 125.

49 PC, p. 129.
} 
propia argumentación, Henry debe recurrir a hechos que la tradición cristiana considera históricos, pero que son imposibles de probar filosóficamente, como la curación del paralítico o la resurrección de Lázaro. A través de tales hechos, en los cuales por medio de su palabra todopoderosa que puede sanar o dar vida, Cristo -nos dice Henry- se revela detentador del poder de Dios ${ }^{50}$. Sin embargo, este recurso, además de sujetar la condición de Dios a la creencia o no en un hecho histórico, tiene, para Henry, la dificultad adicional de que pone dicha legitimación en un hecho que, como histórico que ha sido, está nada más ni nada menos que en el mundo. La conclusión a extraer de todo ello es clara: la legitimación de las palabras de Cristo sobre sí mismo no es filosófica. Reposa explícitamente sobre la Revelación en las Escrituras y su recepción por la fe. De allí que la experiencia de la verdad de estas palabras, como muy bien lo ha señalado Paul Audi, "no sea la experiencia de todo el mundo." 51

\section{EI límite}

El objetivo que guió esta investigación fue determinar en qué medida la filosofía de M. Henry abre un acceso fenomenológico-hermenéutico, esto es, resultante de la explicitación hermenéutica de experiencias propias de cada hombre en tanto tal, a la relación religiosa. Hemos analizado cómo el viraje que se produce en el pensamiento henryano con la reinterpretación en clave cristiana de su filosofía de la vida produce una inversión en la perspectiva del análisis. Ya no se trata de un análisis fenomenológico de la experiencia inmanente de la vida por el viviente, que encuentra su último límite decible en el hecho de que la vida, experimentada como dada, nos remite al impulso de Vida en tanto dación de sí y, así, a una trascendencia en el seno de la experiencia inmanente de la vida. Ahora se trata de un análisis desde la perspectiva de esa Vida misma, de una descripción de su auto-engendramiento en un Archi-Hijo y, consecuentemente, en una Archi-Carne, que son específicamente las del hijo unigénito de la Vida: Cristo, que justifica esta condición de único Primer Viviente y único Verbo encarnado en su propia palabra. Con esta inversión del análisis de la relación del viviente con la dación de la Vida a la de la Vida con los vivientes a través del Archi-Viviente abandona Henry el plano fenomenológico y se sitúa en el plano de la auto-experiencia de la mismísima Vida absoluta. De este modo se cierne sobre su filosofía la sombra de haber traspasado el límite fenomenológico y haberse encaminado hacia el infinito país de la metafísica especulativa. Mas este abandono del plano fenomenológico e inversión del análisis para justificar el cristianismo como única religión verdadera implica al mismo tiem-

50 Cf., $P C$, pp. 157-158.

51 Audi, P. : Michel Henry. Une trajectoire philosophique, París, Les belles lettres, 2006, p. 243. 
po y necesariamente un cierre o restricción del acceso a la relación religiosa a aquellos que no son cristianos, esto es, a todos aquellos que no se cuentan entre los "simples" que tuvieron la "gnosis" de (o directamente habría que decir la fe en) la verdad esencial del cristianismo revelada en las Escrituras. Este acceso, que en realidad no es un acceso, que no abre "un posible camino a" la relación con Dios, sino que se instala en la mismísima experiencia de la dinámica inmanente de la divinidad, no se corresponde con la experiencia de todo hombre en cuanto tal y está reservado sólo a algunos, pocos o muchos.

Pero quien ha pasado el límite ha tenido también la grandeza de haber mostrado el límite, de habernos conducido hacia la "maravilla de las maravillas"52. Y la "maravilla de las maravillas" no es "que el ente es", como creía Heidegger, sino que "se da la vida". La maravilla es que la vida en su esencia, como experiencia patética de sí, sólo remite a su propia dación, y es, así, algo Absoluto. La buena nueva filosófica que Henry transmite a todo hombre no es la de su salvación por la comunión de su carne con la Archi-Carne de Cristo; no es la salvación que esperan los que tienen fe religiosa y, más específicamente, cristiana. La buena nueva que Henry le ha dejado a todo hombre es más modesta; es haber mostrado que el Absoluto no se sitúa en ningún trasmundo metafísico, ni en ninguna luz que le viene al mundo desde cierto trasfondo inasible, ni tampoco en el último postulado de la razón en su uso lógico puro. "El Absoluto no es ni el fruto de una especulación ni el resultado de una deducción." 53 La buena nueva que nos trae Henry es que nosotros padecemos lo absoluto en nuestro seno más íntimo, en la experiencia del habernos sido dada esta vida "que nos da a experimentar todas las cosas dándonos ya siempre patéticamente a nosotros mismos" 54 . A la Vida, que, en tanto pura donación de sí, es acto puro; que, en tanto nos es entregada, nos precede; que, en tanto se manifiesta en cada viviente de un nuevo modo, nos excede; y que, finalmente, en tanto padecida por sí misma (con una "pasividad más pasiva que toda pasividad") nos interpela ab-solutamente - a esta Vida es a quien podemos, tal vez, interpretar como Dios. Dejar escuchar esta interpelación, que resuena en la experiencia de no habernos dado esta vida que experimentamos en nosotros mismos, ofrecer la ocasión de ver la revelación de lo Absoluto en nuestra propia interioridad es la pre-condición (pero también el límite filosófico) de cualquier relación religiosa, comprendida como respuesta a la revelación de lo Absoluto que padece cada hombre en tanto tal. Por ello mismo es posible afirmar, desde una perspectiva fenomenológica y en contra de ciertas interpretaciones teologizantes o cristianizantes ${ }^{55}$, que la importancia

\footnotetext{
52 Tomo la expresión de Paul Audi, op. cit., p. 243.

53 Audi, P., op. cit., p. 244.

54 Audi, P., op. cit., p. 245.

55 Por ejemplo la de Rolf Kühn quien, considera que la realidad crística constituye "la realidad reconocida de una verdad necesaria" que toma sobre sí una fenomenología como la henryana, liberada de una autoconstitución ilusoria. Cf. Kühn, R.: "Le pasaje absolu", en Greisch J. y David A. (eds.). op. cit., p. 162.
} 
del pensamiento de Henry no reside esencialmente en haber confrontado su fenomenología de la vida con la teología cristiana, sino en haber abierto un acceso legítimamente fenomenológico a la relación religiosa o, dicho en otros términos, en haber mostrado que, más acá (y no en contra de) cualquier Escritura Sagrada o cualquier confesión de fe, Dios le habla a todo hombre desde el interior de su propia vida, desde el interior profundo de su propia alma. Es cuestión del hombre volverse o no hacia tales profundidades.

Ángel Enrique Garrido-Maturano

Consejo Nacional de Investigaciones Científicas y Técnicas (CONICET) - Instituto de Investigaciones Geohistóricas (IIGHI), Resistencia, Argentina.

hieloypuna@hotmail.com 